\title{
A literatura como instrumento mobilizador de um aprendizado escolar empírico e autônomo: um estudo entre Brasil e Portugal
}

\author{
Literature as an insturment for mobilizing an empirical and autonomous school learning: a study between \\ Brazil and Portugal
}

\section{José Carlos dos Santos Debus}

Unidade de Educação de Santa Catarina - UNIESC - Florianopolis - Santa Catarina - Brasil

\section{Ângela Maria Balça}

Universidade de Évora - UEv - Évora - Portugal

\begin{abstract}
Resumo: Este texto refere-se a um projeto de pesquisa de pós-doutoramento realizado junto ao Instituto de Investigação e Formação Avançada da Universidade de Évora em Portugal no ano de 2018. Nosso objetivo é analisar a produção ficcional contemporânea do Brasil e de Portugal que inclui obras de natureza literária escritas para a infância que, em nosso entendimento, possam atuar como um aparato mobilizador de educação moral, científica e artística. O referencial teórico dialoga com o campo da educação e da literatura buscando uma concepção de educação escolar emancipadora amparada nos estudos de Freire (2006), Rancière (2007) e Candido (1988). Nosso olhar procurou obras que possibilitassem uma combinação de qualidade no texto e na ilustração dentro de uma perspectiva de arte literária e que não estivesse condicionada por uma estrutura dogmática. Percebemos nesse percurso que o mundo da literatura estimula todas as formas de comunicação se colocando como um espaço de reflexão, de ação e de transformação a partir do confronto entre o conteúdo maravilhoso e o conteúdo "real".
\end{abstract}

Palavras-chave: autonomia do estudante, didática, literatura, pedagogia.

Abstract: This text refers to a postdoctoral research project carried out at the Research and Advanced Training Institute of the University of Évora in Portugal in the year 2018. Our purpose is to analyze the contemporary fictional production of Brazil and Portugal which includes works of a literary nature written for childhood that, in our understanding, can act as a mobilizer of moral, scientific and artistic education. The theoretical reference dialogues with the field of education and literature seeking a conception of emancipatory school education supported by the studies of Freire (2006), Rancière (2007) and Candido (1988). Our look sought works that enabled a combination of quality in text and illustration from a literary art perspective and that was not conditioned by a dogmatic structure. We perceive in this way that the world of literature stimulates all forms of communication, posing as a space for reflection, action and transformation from the confrontation between wonderful content and "real" content.

Keywords: student autonomy, didactics, literature, pedagogy. 


\section{Introdução}

Este texto refere-se a um projeto de pesquisa de pós-doutoramento realizado junto ao Instituto de Investigação e Formação Avançada da Universidade de Évora em 2018. Embora não tenha contado com financiamento público a pesquisa foi executada em dez meses com imersão na Biblioteca Lúcio Craveiro em Braga-Portugal.

Trata-se de um estudo sobre o potencial da literatura como dispositivo mobilizador de um aprendizado escolar empírico e autônomo. Partimos de uma reflexão que entende 0 espaço ensino/aprendizagem a partir de novas configurações geradas pelas transformações nas comunicações e por novas relações sustentadas no respeito mútuo e afetivo entre estudantes e professores, que possibilitam outros movimentos na educação e nos processos de construção do saber, e, esses movimentos, indicam o princípio da autonomia como base à prática pedagógica. Nosso objetivo é analisar a produção ficcional contemporânea do Brasil e de Portugal que inclui obras de natureza literária escritas para a infância que, em nosso entendimento, possam atuar como um aparato mobilizador de educação científica e artística. Trabalhamos com a perspectiva de um estudante autônomo e protagonista em um ambiente de produção do conhecimento, que procura perceber a realidade social e histórica, a partir do ficcional dentro de uma abordagem empírica e científica que explora a interdisciplinaridade entre literatura, pedagogia e didática.

Quando pensamos em autonomia do estudante, devemos entender que não se trata de liberdade plena. Ela depende dos outros, depende do grau de ligação que o sujeito estudante estabelece com os outros em espaço de convivência. Conforme Dubet (2014), o princípio da autonomia está no sentimento e na convicção de se ter um valor próprio ameaçado pela falta dela nas relações do dia a dia.

Um contexto poético e literário pode propiciar ambiente de estudos cativante e envolvido pela afetividade e pela troca de saberes que se afirmam nos processos de construção do conhecimento.
Como escreveu Antônio Candido (1988), a literatura pode ter uma relevância "equivalente à das formas conscientes de inculcamento intencional, como a educação familiar, grupal ou escolar" (p. 175). Para este pensador e crítico da literatura, cada sociedade concebe suas manifestações ficcionais a partir de suas realidades sociais. "Por isso é que a literatura tem sido um instrumento poderoso de instrução e educação, entrando nos currículos, sendo proposta a cada um como equipamento intelectual e afetivo" (1988, p. 175). Esse contexto é envolvido por uma perspectiva de comunicação, em que "a literatura confirma e nega, propõe e denuncia, apoia e combate, fornecendo a possibilidade de vivermos dialeticamente os problemas" (CANDIDO, 1988, p. 175).

Nosso referencial teórico dialoga com o campo da educação e da literatura buscando uma concepção de educação escolar emancipadora que compreende a autonomia do estudante como um princípio e que projeta experiências comprometidas com uma práxis que se movimenta dentro do espaço da construção do saber. Essa concepção de educação escolar se ampara nos estudos de Paulo Freire $(2006,2007)$ e Jacques Rancière (2007), cujas produções formam um conjunto sobre/de o pensamento emancipador na educação e nos permite uma reflexão sobre a compreensão da experiência ensino/aprendizagem dentro do campo da autonomia. Para Rancière (2007), a igualdade é uma condição necessária nas relações de ensino e de aprendizagem e a autonomia intelectual deve ser uma meta nos fundamentos da pedagogia. A perspectiva freiriana do sujeito também aponta para a apropriação e experimentação do poder de recriar o mundo. Entender que o respeito à autonomia, à dignidade e à identidade do sujeitoestudante deve levar algumas virtudes e qualidades para as novas vivências (FREIRE, 2007, p.69). Para Freire, as experiências e práticas autônomas não devem restringir-se ao espaço da escola, mas ocupar todo o espaço vital para o sujeito.

Para dimensionarmos a literatura e suas possibilidades didáticas, retomamos Antônio Candido (1988), o qual acredita que toda criação de toque 
poético, ficcional ou dramático, em todos os tipos de cultura, das formas mais simples às formas mais complexas, possui um caráter de coisa organizada e "torna-se um fator que nos deixa mais capazes de ordenar a nossa própria mente e sentimentos; e em consequência mais capazes de organizar a visão de mundo que temos" (p. 177). Para ele, a produção ficcional tira as palavras do nada e as ordena como um todo articulado. Portanto, a literatura pode ser um instrumento "organizador e humanizador" (CANDIDO, 1988, p. 177).

No campo da literatura infantil e juvenil, encontramos nos estudos e nas reflexões de Ângela Balça $(2010,2013,2015)$ e Eliane Debus (2010) o entendimento e a aproximação necessária da literatura infantil e juvenil na perspectiva lusobrasileira. Balça tem buscado sistematizar essa literatura no âmbito de Portugal nas últimas décadas e apresenta algumas técnicas que possibilitam aos educadores de forma geral que se deixem envolver pelos textos literários e mobilizem as crianças e os jovens de uma forma consciente e criativa num processo que pressupõe um estudante autônomo. Eliane Debus (2010), assim como Freire (2006), enfatiza que a criança traz consigo a leitura do mundo e aponta a contribuição da figura do mediador no processo de leitura e no processo de construção do conhecimento a partir da leitura de textos que não falam diretamente da realidade. De textos que tratam de um mundo que não é, mas que pode nos oferecer categorias de um mundo que é. Reforçando assim a singularidade do texto literário e sua relativa autonomia do real (DEBUS, 2010, p. 207).

Nosso percurso metodológico foi guiado pela hipótese das obras literárias recriarem um modelo empírico de construção do conhecimento baseado na autonomia, na independência e no protagonismo do estudante. Por isso, direcionamos nossa análise para o potencial pedagógico e didático e também para o potencial de representatividade do mundo físico, político, social e cultural. Tomamos as produções literárias como uma fonte importante de conhecimento dessas representações e de suas realidades possíveis na contemporaneidade. Entre elas, a de representar situações que contribuam para novas reflexões nas relações de ensino e aprendizagem.

Nossa pesquisa passou por duas fases. $\mathrm{Na}$ primeira, fizemos um levantamento da produção literária para a segunda infância e selecionamos os livros para análise; na segunda, analisamos as obras selecionadas. Com o intuito de preparar a análise e o percurso literário-educativo, utilizamos o conceito de configuração textual proposto por Rosangela Marquezi (2018), por meio do qual devemos considerar todos os aspectos e singularidades que compõe o texto literário. Marquezi (2018) propõe que é possível "unir o estético e o formativo, conciliando o lúdico, a busca da fantasia e da sensibilidade, passando sempre pela plurissignificação da linguagem - pressuposto importante para que o texto se qualifique esteticamente" (p. 117). Marquezi (2018) também chama a atenção para a dificuldade que podemos ter para encontrar o ponto de equilíbrio entre o estético e o formativo sem cair no "utilitarismo" (p. 120). Edmir Perrotti (1986) reforça essa preocupação, afirmando que a expressão estética não é pura, nela estão sempre presentes as instâncias ideológicas que podem revelar um caráter mais instrumentalista da expressão literária. Este autor alerta para a inevitável questão do "discurso estético" em oposição ao "discurso utilitário" e afirma que a literatura infantil deve ser útil e não utilitarista. Candido também chama a atenção para essa questão quando diz que a literatura "é uma construção de objetos autônomos com estrutura e significados. No entanto ela não é um tipo de instrução" (CANDIDO, 1988, p. 176).

Assim, na fase de seleção, nosso olhar procurou obras que possibilitassem uma combinação de qualidade no texto e na ilustração dentro de uma perspectiva de arte literária e que não estivesse condicionada por uma estrutura dogmática, mas que permitisse uma análise a partir de pressupostos da educação escolar que considere a criatividade, a experimentação e a viabilidade de reelaboração do real. Fizemos a leitura de mais de 80 obras da literatura infantil e juvenil produzidas por autores 
portugueses e brasileiros e selecionamos seis livros para análise. Para este artigo, trouxemos as obras 0 Conto da llha desconhecida, do escritor português José Saramago, e Água de Anil, da brasileira Nilma Lacerda. Que apresentamos a seguir.

\section{A literatura como instrumento mobilizador do aprendizado escolar}

2.1 As ilhas conhecidas que são desconhecidas

O livro O Conto da llha desconhecida, de José Saramago (2015), é indicado pelo Plano Nacional de Leitura para $08^{\circ}$ ano em Portugal. Nossa análise considerou o potencial da obra e o estudo da geografia física, política e social e da filosofia. Com uma narrativa cronológica e linear, com parágrafos longos, sem travessão nos diálogos e com pouca pontuação, uma característica da obra do autor, Saramago conta a história de um homem que vai pedir ao rei um barco para encontrar uma ilha desconhecida. Mas a personagem encontra vários obstáculos, desde a petição que deveria ser encaminhada a um rei que vive muito distante de seu povo, até as dificuldades de encontrar um barco que pudesse navegar em águas profundas e levá-lo até a ilha desconhecida. Assim, o texto vai contornando suas personagens e identificando-as apenas pelos nomes das suas profissões mostrando uma hierarquia e uma ordem social que destaca as desigualdades daquele sistema de governo: uma monarquia.

A narrativa segue apresentando o protagonista - inicialmente ele é o homem que queria um barco, depois fica conhecido como o homem que tinha um barco e, por fim, o homem do leme - como um sujeito inquieto que ainda acredita que existem ilhas a serem descobertas e que vai buscar seus sonhos, mas é impedido pela futilidade do cotidiano. Mas ele não desiste, "Quero encontrar a ilha desconhecida. Quero saber quem eu sou quando nela estiver" (SARAMAGO, 2015, p. 43).

O conto de Saramago possibilita várias leituras. Podemos explorá-lo no campo da Filosofia a partir de uma interpretação mais intimista que nos possibilita compreender que, as vezes, se faz necessário sairmos de nossa zona de tranquilidade para nos conhecermos melhor: "Se não sais de ti, não chegas a saber quem és" (SARAMAGO, 2015, p. 43). Ou, como diz o filósofo do rei, "todo homem é uma ilha [...] que é necessário sair da ilha para ver a ilha, que não nos vemos se não nos saímos de nós próprios" (SARAMAGO, 2015, p. 43). Também podemos compreender que o barco que o homem tanto quer é a ilha desconhecida ou, também, a nossa própria vida pode ser uma ilha desconhecida a partir do momento que rompemos os destinos prontos, préformados em busca da nossa própria construção do percurso. Nesse sentido há muitas ilhas desconhecidas. Que nem todas as ilhas estão mapeadas e que nem todos os caminhos estão prétraçados. Tudo isso é um processo pessoal e intransferível. Um processo difícil, mas que dá sentido às nossas vivências e nos põe sempre em busca de mais liberdade.

A narrativa de O Conto da llha desconhecida vislumbra uma grande metáfora sobre vida, permitindo uma proximidade da obra literária com a Filosofia. Mas também é possível avistar um mundo de formas e relevos, rios e ilhas e compreender a diversidade da representação cartográfica. Temas que estão previstos, em Portugal, para o $7^{\circ}$ ano do $3^{\circ}$ ciclo (PORTUGAL 1, 2018). No Brasil, conforme a Base Nacional Curricular Comum, a temática está prevista no programa de ensino do $8^{\circ}$ ano do ensino fundamental a partir da unidade temática "formas de representação e pensamento espacial" com o tópico "cartografias: anamorfose, croquis e mapas temáticos da América, África e Europa” (BRASIL, 2018, p. 388).

Assim, o homem que queria um barco para encontrar a ilha desconhecida vai enfrentar a burocracia governante e o próprio governante em busca do seu sonho. Falar com o rei era uma coisa impensável para os simples mortais. Mas o homem que queria um barco acreditava que o rei "haveria de sentir-se curioso de ver a cara de quem, sem mais nem menos, com notável atrevimento, o mandara chamar" (SARAMAGO, 2015, p. 19). E lá estava ele em frente de Sua Majestade: "Que ilha desconhecida, perguntou o rei disfarçando o riso, como se tivesse na 
sua frente um louco varrido, dos que têm a mania as navegações [...]. Já não há ilhas desconhecidas" (SARAMAGO, 2015, p. 22). E o homem que pedia um barco ao rei responde: "Quem foi que te disse, rei, que já não há ilhas desconhecidas" (SARAMAGO, 2015, p. 22). Os geógrafos do rei "declararam que as ilhas por conhecer é coisa que se acabou desde há muito tempo" (SARAMAGO, 2015, p. 59). Apesar de o rei achar a ideia do homem um absurdo, ele deu-lhe o barco: "Vou dar-te um barco, mas a tripulação terás de arranjá-la tu, os meus marinheiros são-me precisos para ilhas conhecidas" (SARAMAGO, 2015, p. 26).

Acreditamos que uma grande parte das ilhas que compõe o território português é desconhecida. As mais conhecidas são aquelas que compõem os arquipélagos da Madeira e dos Açores. No entanto, até o início do século $X X$, uma parcela considerável da população portuguesa desconhecia as ilhas dos açores. E foi um livro de literatura de viagem, As Ilhas Desconhecidas, de Raúl Brandão, o qual teve sua primeira edição em 1926, que tirou o arquipélago do desconhecimento e produziu um conceito de insularidade (NETO, 2017) que inclui os açores na perspectiva de Portugal. Trata-se de um relato de uma viagem pelos arquipélagos dos Açores e da Madeira durante o verão de 1924. Para alguns críticos (NETO, 2017), o livro de Raúl Brandão tornase um clássico da literatura de viagem em Portugal.

Entendemos que é possível compreender alguns aspectos da Geografia a partir das inquietações proposta pela narrativa de Saramago. Depois de uma leitura atenta e do debate mediado pelo viés estabelecido por professor e estudante, pode-se, por exemplo, dar início a uma busca pelas ilhas conhecidas (que estão nas cartografias) e, no entanto, são desconhecidas. Cada estudante deve pegar o seu barco e um mapa, e procurar por sua ilha dentro do território de Portugal. Seguindo a perspectiva literária, os estudantes podem construir suas próprias narrativas a partir de suas pesquisas. Aqui, literatura e geografia dão as mãos (BOIRA, 2012) e através dessa interdisciplinaridade se constrói o conhecimento, partindo do ponto vista do estudante. Essa mediação terá o texto literário, que é comum ao professor e aos estudantes (RANCIÈRE 2007), como ponto de partida e como ponto estruturante dos objetivos estabelecidos pelo planejamento do professor.

É muito importante para as relações de ensino e aprendizagem na perspectiva da autonomia dos estudantes e da sua formação integral que o professor planeje e crie conjunturas para que estes possam perceber e utilizar métodos, como a experimentação, a observação, a descrição, a similaridade. Também, para que percebam suas capacidades de sintetizar e expressar esses métodos, levando em conta as correspondências que se apresentam entre o meio físico-ambiental, social, econômico e cultural, onde se desenvolvem os grupos sociais e a natureza em suas estruturas formativas.

\section{0 meio ambiente a partir da literatura}

A relação entre $o$ homem e a natureza foi durante muito tempo uma condição intrínseca no contexto da literatura, desde o imaginário mais clássico que aflorava a partir dos quatro elementos básicos - o ar, a água, a terra e o fogo -, que possibilitavam e potencializavam a vida humana, e orientavam as narrativas literárias que envolveram grandes personagens da ficção. A literatura mais contemporânea também tem abordado esse tema, mas do ponto de vista da degradação do planeta e da vida, e do menosprezo provocado pela lógica do mundo moderno e industrial.

Conforme Debus e Debus (2019), o tema da natureza sempre foi recorrente nas narrativas para a infância. Apesar de que, em alguns momentos, assumiu um caráter mais ufanista e nacionalista, como é o caso de Olavo Bilac e Monteiro Lobato nas primeiras décadas do século $X X$ : "sabe-se que a temática se sobressai a partir do final da década de 1970, trazendo para o cenário da escrita para infância e juventude a denúncia de depredação da natureza pela mão humana [...]" (p. 6). 
Em Portugal, a temática do meio ambiente na literatura para a infância também se sobressai a partir dos anos de 1970, principalmente após a revolução dos cravos em abril de 1974, que, segundo Azevedo e Balça (2017), "possibilitou o derrubar da Ditadura e o instaurar da Democracia bem como a consequente abolição da censura; [...]" (p.22). Destacou-se nesse período o escritor Sidónio Muralha com a obra Valéria e a Vida, publicada pela primeira vez em 1976, e continuou sendo editada nas décadas seguinte em Portugal, onde faz parte do Plano Nacional de Leitura. $\mathrm{Na}$ atualidade também está publicada no Brasil. (AZEVEDO; BALÇA, 201 p. 26).

O tema do meio ambiente é previso no sistema de ensino português a partir do segundo ciclo do $6^{\circ}$ ano, onde se estuda os "processos vitais comuns aos seres vivos e as agressões do meio e a integridade dos organismos" (PORTUGAL 2, 2018, p. 2). No Brasil, a temática está prevista na Base Nacional Comum Curricular (BNCC) no ensino de Ciências para $07^{\circ}$ ano do ensino fundamental com a unidade temática "vida e evolução", tendo como ponto específico do conhecimento a "diversidade de ecossistemas e os fenômenos naturais e os impactos ambientais". E também no ensino de Geografia para o 6ำ ano do ensino fundamental com a unidade temática "natureza, ambientes e qualidade de vida", a partir de tópicos como "biodiversidade e ciclo hidrológico" (BRASIL, 2018, p. 343; 382).

Para analisar a temática do meio ambiente na atualidade a partir da literatura infantil, escolhemos a obra Água de Anil, da brasileira Nilma Lacerda (2014). Trata-se de uma escrita que não segue uma sequência e é composta de vários discursos, como o rol da lista de roupas, a dramaturgia e o memorialístico. O que move a trama é a personagem de Rosalvo, filho da lavadeira Dinalva que, desde muito cedo, aprende a ler o rol da lista de roupas que sua mãe lavava no rio. Por conta da sua habilidade com a leitura, Rosalvo é mandado à escola e se destaca no seio da família, e também da comunidade. Rosalvo cresce defendendo as águas límpidas dos rios e vai trabalhar em um jornal que potencializa sua voz em defesa do meio ambiente. Por conta disso, e da sua empatia com a natureza, elege-se vereador e em seguida deputado. Sempre com um discurso de defesa dos rios e das florestas. No decorrer da sua atuação política, as suas falas e sua prática vão se modificando em decorrência do lobby político do agronegócio. Angustiado e consciente de que seus ideais de mocidades foram por água abaixo, Rosalvo retorna a sua gente em busca da sua infância e do anil que era usado para limpar as roupas.

A narrativa de Água de Anil mostra que durante muito tempo não havia preocupação alguma com a poluição das águas: "[...] ou se era vendo a água correr rio abaixo. Espuma de sabão coroando a corredeira. Para onde ia toda aquela sujeira? [...] A mãe não tinha resposta [...] Vez que outra, aparecia o mar na conversa, o rio levava a sujeira para o mar" (LACERDA, 2014, p. 12). É assim que Rosalvo teve suas primeiras inquietações sobre a relação do homem com a natureza.

E são essas inquietações que vão formar uma consciência ecológica em Rosalvo: "Somos seres do progresso e das conquistas tecnológicas [...]. Habitantes de um mesmo planeta precisamos tomar consciência de que todas forma de vida deve ser respeitada [...]" (LACERDA, 2014, p. 23). Para ele, "As lavadeiras tinham desde muito tempo uma visão ecológica [...] Elas sabiam do uso das plantas em seu ofício, realizado com sustentabilidade e, no entanto, foram acusadas de poluição" (LACERDA, 2014, p. 22). Quando as leis ambientais começaram a ser feitas, no caso do Brasil, a partir dos anos 1980, as práticas de lavar roupas nas águas dos rios foram se perdendo, um pouco disso também foi causado pelo fato das águas dos rios estarem poluídas. Embora o costume ainda permaneça em algumas regiões do Brasil.

Rosalvo cresce e vira político. Elege-se vereador: "Flashes de programas de televisão com Rosalvo defendendo o meio ambiente [...] precisamos defender as águas do rio. Do nosso rio e de todos os outros. É a própria sobrevivência da humanidade" (LACERDA, 2014, p. 27). As falas do vereador se ampliam por todos os cantos e Rosalvo vira deputado estadual: "Discurso bonito e inflamado, ele faz bela 
figura, sempre muito bem na fita, rádio e televisão. Água pura é cultura, quilombola, nação indígena, cabocla e caipora, é tudo bola da vez" (LACERDA, 2014, p. 30). E com isso, ele já é deputado federal. Mas Brasília e a Câmara Federal são outras coisas.

Toda a sua fala bonita em defesa da natureza, assim como seus ideais, perdem-se no emaranhado jogo de poder: "Me calavam com argumentos fortes, uma coisa era falar a população, outra bem diferente era fazê-lo naquela Casa" (LACERDA, 2014, p. 39). Lá o que prevalecia era a força dos grandes grupos econômicos em favor do desmatamento e pela ampliação do cultivo da soja e de outros cereais: "Meus protestos se afogaram em água pouca. Engoli a seco, voltei para o gabinete" (LACERDA, 2014, p. 41).

No capítulo 5 aparece outro narrador, o "Garoto do Blog". Aqui a abordagem põe duas perspectivas em debate. Os movimentos normais da natureza, como a ação dos ventos, as chuvas, as secas, os frios e ação humana. Uma coisa é extinguir por conta desses fenômenos: "Agora, extinguir porque usamos pesticida a torto e a direito, pescamos em hora errada, caçamos indiscriminadamente, sujamos o habitat alheio, interferimos nas sementes, isso, façam-me o favor, é inteiramente evitável e injusto" (LACERDA, 2014, p. 45).

Esse momento da narrativa é oportuno para construir um estado da arte com os estudantes. A partir dos seus conhecimentos e das memórias de seus familiares, amigos e conhecidos é possível produzir um conhecimento, mesmo que seja com os fragmentos dessas memórias sobre a relação do homem com o meio ambiente num passado não muito distante, e quais eram as práticas e atitudes do ser humano para com esse meio e como essas atitudes influenciavam-no: "É hora de procurar no passado, tanto quanto inventar no futuro [...] a manutenção da vida com v maiúsculo" (LACERDA, 2014, p. 22).

O narrador também chama a atenção para a vida dos seres humanos que não participam das decisões por serem excluídos do processo e por serem envolvidos no discurso desenvolvimentista do capitalismo industrial que nos faz consumir mais do que necessitamos e nos põe diante da "dialética do conforto": "Queremos um planeta saudável, mas buscamos luxo e comodidades que exigem enormes dispêndios de recursos naturais" (LACERDA, 2014, p. 45).

A abordagem inicial pode ser feita a partir do confronto entre o consumo e o desenvolvimento sustentável para se compreender aquilo que são fenômenos naturais e os seus impactos ambientais e aquilo que são fenômenos provocados pela ação humana no meio ambiente. É um bom momento para lembrar grandes tragédias ambientais provocadas por empresas mineradoras no Brasil. Como a morte do Rio Doce e de muitas pessoas em Mariana, Minas Gerais, que foi sufocada por toneladas de lama tóxica, que eram resíduos armazenados sem o devido cuidado por uma empresa mineradora e, mais recente, o rompimento da barragem de Brumadinho, também em Minas Gerais, onde um mar de lama também tóxica inundou casas, ruas e rios, causando a morte de muita gente e também da natureza.

O protagonista de Água de Anil que inicialmente tinha uma relação muito consciente com as questões do meio ambiente é envolvido pelas forças políticas das grandes empresas em nome da prudência e da moderação exigidas por esses grandes grupos econômicos que, juntos com os políticos, fazem leis que permitem que a cultura da soja avance sobre as veredas e sobre as áreas de proteção ambiental: "A soja tem um impacto enorme no produto interno bruto. Cerrado não alimenta ninguém. Nem faz justiça social" (LACERDA, 2014, p. 54), diz Rosalvo.

Essa é uma prática política que se funde numa concepção que vê somente a possibilidade do lucro financeiro. $\mathrm{Na}$ perspectiva políticopedagógica de Freire (2006), isso pode ser compreendido pelos estudantes a partir de ideias e práticas, desenvolvidas por eles mesmos, que tragam para o debate formas sustentáveis de produzir alimentos sem o risco de destruir a natureza.

A interface entre o universo ficcional de Águas de Anil e os espaços que compõe o meio físico e 
geopolítico de sua narrativa aproxima o estudante de seus anseios, e amplia sua visão de mundo reforçando a perspectiva do autoconhecimento e do aprendizado autônomo. No contexto da pedagogia freireana, é importante que o estudante se reconheça como um destruidor da natureza e procure encontrar modelos de desenvolvimento que sejam comprometidos com a recuperação e preservação do meio ambiente em que ele habita, bem como a sua comunidade. Aqui, estudantes e professores podem trabalhar o conceito de desenvolvimento sustentável a partir de práticas que viabilisem o bom uso dos recursos naturais.

\section{Considerações finais}

Não foi nossa intenção mostrar um manual de como trabalhar os conteúdos curriculares a partir da literatura, mas, com alguns exemplos, destacar o potencial da literatura como recurso didático e pedagógico, sua capacidade motivadora no campo do ensino e da aprendizagem, e a sua diversidade e expectativas de outros olhares e reflexões sobre os temas escolares, fornecendo contribuições que possibilitem ao leitor/estudante encontrar a sua própria maneira de estudar.

O papel do professor como mediador entre 0 estudante, o mundo físico e o mundo metafísico faz toda a diferença nas relações autônomas. É aqui que a arte do texto literário se coloca como uma ferramenta mobilizadora e facilitadora da capacidade imaginativa durante o processo de construção do conhecimento. Assim, a estrutura da prosa pode ser entendida como um espaço de reflexão, de ação e de transformação, a partir do confronto entre o conteúdo maravilhoso e o conteúdo "real".

Pudemos perceber na narrativa Água de anil uma preocupação profunda sobre a relação do homem com o meio ambiente no passado e no presente, e que identifica as práticas e atitudes do ser humano para com esse meio, e como essas atitudes influenciam diretamente a composição desse meio. Desmatamento, queimadas, efeito estufa, monocultura e promessas de políticos são grandes assuntos para abordar em sala de aula e as ideias sobre o comportamento humano manifestadas na narrativa de Nilma Lacerda e também na narrativa de José Saramago funcionam como dispositivos para compreender questões tão reais que estão cotidianamente nos noticiários.

Observamos que a narrativa de $\mathrm{O}$ conto da ilha desconhecida não aproxima a obra literária com o conteúdo disciplinar. Como foi o caso de Água de anil. No entanto, as metáforas que movimentam seu enredo nos possibilitam ir além dos limites da narrativa e construirmos nossas próprias metáforas para compreendermos aquilo que as grades curriculares estabelecem em suas bases.

Em todo nosso percurso de pesquisa, consideramos que a literatura pode funcionar como um processo de comunicação que fomenta ideias de construção do conhecimento e cria uma relação de igualdade na aquisição desse conhecimento a partir de algo que é comum (o livro) ao professor e ao estudante e que procura respostas do leitor que é convidado a explorar a obra literária das mais variadas formas.

\section{Referencias}

AZEVEDO, F.; BALÇA, A. (2017). Os primórdios da relação entre literatura para a infância e ambiente em Portugal. Textura - Revista de Educação e Letras. Vol. 19, no 19, p. 26-38 Canoas: jan/abr 2017.2017.

BALÇA, Angela. A leitura de literatura - algumas reflexões no contexto educativo português. In: PONTES, V.M.A; SILVA, L.G.S.; BATISTA, C.S. (Org.). Trilhas Pedagógicas. Curitiba: CRV, 2013. $174 \mathrm{p}$.

BALÇA, Angela.; MAGALHÃES, Olga; COSTA, Paulo. (Org.). Visto de lá: a corte portuguesa no Brasil contada aos mais novos. Educare/Educere. Castelo Branco: Escola Superior de Educação de Castelo Branco, Edição fora de série, 2010, p.183195.

BOIRA, J. V. Literatura y geografia se dan la mano. A propósito de la novela "El mapa y el território". Revista Bibliográfica de Geografia y Ciencias Sociales da Universidade de Barcelona. VOI. XVII, no 995. Barcelona: octubre de 2012. p. 81-94.

BRASIL. Base Nacional Comum Curricular/MEC. 2018. 
CÂNDIDO, Antônio. O direito à literatura. In: CÂNDIDO, Antônio. Vários escritos. São Paulo: Ouro sobre azul, 1988. 180 p.

COSSON, R. Lentamente literário. Teoria e prática. São Paulo: Contexto, 2006. 144 p.

DEBUS, Eliane. Reflexões sobre o critério de escolha do livro literário nos anos iniciais do ensino fundamental. In: RÖSING, T.M.K; BURLAMAQUE, F.V. (Orgs.). De casa e de fora, de antes e de agora. Passo Fundo: Editora da Universidade de Passo Fundo, 2010. p. 132-146

DEBUS E.; DEBUS J.C.S. As poéticas de cuidado com o meio ambiente na literatura infantil e juvenil brasileira. Revista Dialogia. Vol. 3, № 30, p. 35-46. São Paulo: set/dez, 2018.

DUBET, François. Injustiças: a experiência das desigualdades no trabalho. Florianópolis, SC: Editora da UFSC, 2014. 406 p.

FREIRE, Paulo. Pedagogia da Autonomia: saberes necessários à prática educativa. 34. ed. São Paulo: Paz e Terra, 2006. 144 p.
FREIRE, Paulo. Pedagogia do Oprimido. 48. reimpressão. São Paulo: Paz e Terra, 2007. 256 p.

LACERDA, Nilma. Água de Anil. São Paulo: DSOP, 2014. $80 \mathrm{p}$

MARQUEZI, Rosangela A. (2018) Ou isto ou aquilo a (há) poesia além da pedagogia. In. Debus, Eliane; Bazzo, Jilvania; Bortolotto, Nelita. (Orgs.) Poesia (cabe) na escola. Campina Grande: EDUFCG, 2018. p. 127-141.

PORTUGAL 1. Geografia. Documentos curriculares de referência para o $3^{0}$ ciclo. Direção Geral de Educação/MEC. 2018.

PORTUGAL 2. Ciências naturais. Documentos curriculares de referência para o $2^{\circ}$ ciclo. Direção Geral de Educação/MEC. 2018.

SARAMAGO, José. O Conto da ilha Desconhecida. Porto: Porto Editora, 2015. 64 p.

RANCIÈRE, J. O Mestre Ignorante. Belo Horizonte: Autêntica. 2007. 192 p.

\section{COMO CITAR ESSE ARTIGO}

DEBUS, Jose Carlos dos Santos; BALÇA, Ângela Maria. A literatura como instrumento mobilizador de um aprendizado escolar empírico e autônomo. Um estudo entre Brasil e Portugal. Signo, Santa Cruz do Sul, v. 44, n. 81, 2019. dez. ISSN 1982-2014. Disponível $<$ https://online.unisc.br/seer/index.php/signo/article/view/13758>. Acesso em: doi: https://doi.org/10.17058/signo.v44i81.13758. 